
Artist: $\quad$ Kim Huynh
Title: "If I Had a Hammer"
Medium: $\quad$ Mixed Media and Print-Installation
Solo Exhibition 621 Gallery, Department of Art
University of Calgary

Date: $\quad$ May 15-20, 2016

\title{
Introductory Notes
}

The installation is an abstract representation of significant aspects of dominant minority relationships in Canadian history.

The series of five photographs submitted to the CPI Special Issue, Fall 2016, consist of the following:

- Photographs One and Two: A massive mural;

- Photograph Three: The Horse and Saddle;

- Photograph Four: The wooden file cabinet;

- Photograph Five: Depictions of inequality.

Photographs One and Two: A massive, arresting wall to wall, and floor to ceiling mural. The documents displayed on the mural are the vital backdrop for the installation. The mural represents the progress of Canadian society in regards to social justice issues.

The mural occupying the entire wall focuses on four pivotal years which have shaped society in Canada: 1854; 1947; 1960 and 2016.

These years correspond, respectively, to:

- The abolition of the feudal system in Canada;

- The abolition of the Chinese head tax;

- The establishment of the Canadian Bill of Rights; and,

- The beginning of the process of reconciliation with Canada's Indigenous communities. 
Photograph Three: The Horse and Saddle (sitting proudly, at the centre of the room). The dominant image of the horse is significant as it embodies the connections between the four stories (see Photograph Two). It encapsulates the progression of Canadian history and the continued challenges between diversity and inequality. The horse, as importantly, symbolizes the Royal Canadian Mounted Police (RCMP).

Photograph Four: The wooden file cabinet (sitting propped, on the back of the saddle). The wooden file cabinet riddled with holes represents the emotional response of the artist towards the injustices and violence done to minority cultural groups by successive Canadian governments.

\section{Photograph Five: Depictions of Inequality.}

(In reality, the two images in the photograph, were two separate, three dimensional models. Each one was placed on a diagonal line. (One to the southwest and the second to the northeast of the horse and saddle). Each one was attached to the back of the saddle with a lengthy knotted string of the artist's personal scarves).

The larger three dimensional piece (model), the meat tenderizer is representative of the underrepresentation that the Asian art community has received and continues to receive in Canada. The far smaller piece (3D model), depicts the increasing presence of Asian artists. The piece as a whole expresses differences in lived realities of dominance and oppression.

Concluding Remarks: Despite major demographic changes, due to significant increases in immigration from the south, and population growth of First Nations Peoples in the mid to late $20^{\text {th }}$ Century, Canadian institutions, policies and practices have generally, failed to keep up with and respond positively to such changes.

Cultural and Pedagogical Inquiry, Fall 2016, 8(2), pp. 46-48 
The faces of Canada have changed forever.

"If I had a hammer...

It's the hammer of Justice,

It's the bell of freedom...".

(Originally by Pete Seeger \& Lee Hays (1949), later sung by Peter, Paul and Mary, and during the Civil Rights social movement).

\section{Editor's Note:}

Kim's art installation marks a special place in the evolution of the CPI Special Issue "Still I Rise: A tribute to Maya Angelou". The work exemplifies, for example: cultural separation, formation of identity and, systemic and structural biases of iconic Canadian institutions which have had/ still have negative impacts on certain ethnic and racial groups. 